\title{
Visibility of retractions: a cross-sectional one-year study
}

Evelyne Decullier ${ }^{1,2,3^{*}}$, Laure Huot ${ }^{1,2,3}$, Géraldine Samson ${ }^{1,2,3}$ and Hervé Maisonneuve ${ }^{2}$

\begin{abstract}
Background: Retraction in Medline medical literature experienced a tenfold increase between 1999 and 2009, however retraction remains a rare event since it represents $0.02 \%$ of publications. Retractions used to be handled following informal practices until they were formalized in 2009 by the Committee on Publication Ethics (COPE). The objective of our study was to describe the compliance to these guidelines.

Methods: All retractions published in 2008 were identified using the Medline publication type "retraction of publication". The notices of retraction and the original articles were retrieved. For each retraction, we identified the reason for retraction, the country of affiliation of the first author, the time to retraction, the impact factor of the journal and the mention of retraction on the original article.
\end{abstract}

Results: Overall, 244 retractions were considered for analysis. Formal retraction notices could not be retrieved for 9. Of the 235 retractions available (96\%), the reason was not detailed for 21 articles (9\%). The most cited reasons were mistakes (28\%), plagiarism (20\%), fraud (14\%) and overlap (11\%). The original paper or its location was found for 233 retractions (95\%). Of these, $22 \%$ were available with no mention of the retraction.

Conclusion: A standard retraction form could be helpful, with a check list of major reason, leaving the editor free to provide the reader with any further information. Original articles should remain available with a clear mention of the retraction.

Keywords: Retraction of publication, Scientific misconduct, Guidelines

\section{Background}

The process of scientific communication relies on trust: the researcher is supposed to conduct his research according to Good Practice, they should report the results properly [1] and declare any conflict of interest [2]. It is difficult for reviewers to detect errors or suspected fraud [3]. Their task is to improve the paper. Various types of inappropriate behavior can be encountered during the writing of a paper and the review process, including misconduct, faked data, falsification, ethical misconduct, plagiarism, etc. [4]. Mistakes, i.e. misinformation without intent, can also diminish the quality of scientific evidence [5]. In cases of scientific misconduct or mistakes, it is necessary that readers are informed,

\footnotetext{
*Correspondence: evelyne.decullier@chu-lyon.fr

${ }^{1}$ Hospices Civils de Lyon, Pôle Information Médicale Evaluation Recherche,

Unité de Recherche Clinique, Lyon F-69003, France

${ }^{2}$ RECIF, EAM Santé Individu Société 4128, Université de Lyon, Lyon F-69003, France

Full list of author information is available at the end of the article
}

which is why the editor later publishes a correction (correcting a mistake by substituting correct information), expression of concern (issued in case of suspected misconduct, not yet proven) or retraction (published in case of proven misconduct) [6,7].

Following the Joachim Boldt case with 88 retractions [8] and the Scott Reuben case with 21 falsified papers [9], the subject of retraction was studied in 4 dedicated publications in 2011 [5,10-12]. The number of retractions in journals covered by the Science Citation Index Expanded has increased 20 times i.e. a tenfold increase since there has been a twofold increase in articles production between 1990 and 2008 [13]. A similar tenfold increase was found when focusing on Medline only (1999-2009), although retraction remains a rare event since it only represents $0.02 \%$ of publications [10].

The Committee on Publication Ethics (COPE) has established guidelines on dealing with retractions in 2009 [14]. COPE recommends that retractions should
C Biomed Central

(c) 2013 Decullier et al.; licensee BioMed Central Ltd. This is an Open Access article distributed under the terms of the Creative Commons Attribution License (http://creativecommons.org/licenses/by/2.0), which permits unrestricted use, distribution, and reproduction in any medium, provided the original work is properly cited. 
be issued in case of unreliable findings (misconduct or error), plagiarism or unethical research.

To better understand the reasons for retractions, 5 studies investigated cohorts of retraction notices (sometimes leading to more than one publication) [10-12,15-18]. All these studies covered different time periods, different durations of time, and provided the rate of retractions related to mistakes (research error and inability to reproduce the results). The rates of retractions related to mistakes tended to decrease according to the last year investigated: $55 \%$ for 1997 [17], 62\% in 2002 [15], 42\% in 2004 [16], 39\% in 2008 [10] and 32\% in 2010 [11].

COPE's guidelines also state that notices of retraction should clearly identify the retracted article (title and authors) and be linked with the retracted article. The notices should be available freely and state the reason for retraction (without being defamatory) and who is retracting. Steen found that $45 \%$ of retracted papers were either available without any mention or deleted [11].

We analysed retractions published in Medline over a single year period to describe the conformity with retraction guidelines as well as the reasons for retraction and their distribution across countries.

\section{Methods}

\section{Data extraction (August, 22th 2011)}

All retractions published in 2008 were identified using the Medline publication type "retraction of publication". The year 2008 was chosen to ensure that all notices of retraction to be correctly indexed at the time of the data extraction. We retrieved the retraction notice and the complete original article for all retractions. All documents were retrieved through the internet, and we did not search paper journals from the local medical library. For each retraction notice, we recorded the numbers of articles retracted, the time to retraction (number of years elapsed between publication of the original paper as noted on the pdf format, and the 2008 publication of the retraction), the country of affiliation of the first author (according to the address of the first author which is usually the same country as the last author, and often the country where the research was done), the impact factor of the journal in 2008 and the reasons for retraction. For the reason for retraction, we used the terminology agreed upon between investigators (Table 1).

Data were extracted by GS, then LH and ED independently reviewed the reasons for retractions. Discrepancies were resolved by consensus between the two reviewers.

\section{Analysis}

We described the frequency of each reason, and crosstabulated it with the country to obtain the ranking of countries for each reason.

$\begin{array}{ll}\begin{array}{l}\text { Table } \mathbf{1} \text { Reasons used to classify retractions: proposed } \\ \text { definitions }\end{array} & \begin{array}{l}\text { Falsified data, fabricated data } \\ \text { Fraud }\end{array} \\ \begin{array}{l}\text { Inconsistent data } \\ \text { Mistakes }\end{array} & \begin{array}{l}\text { Mistakes concerning data found in the paper } \\ \text { raised by the author(s) } \\ \text { Publication of data or text already published } \\ \text { by others }\end{array} \\ \text { Overlap } & \begin{array}{l}\text { Multiple publication of same data or } \\ \text { self-plagiarism }\end{array} \\ \text { Property or legal concerns } & \begin{array}{l}\text { Publication of elements without obtaining } \\ \text { permission } \\ \text { Concerns on the ethical validation of the }\end{array} \\ \text { Ethics } & \begin{array}{l}\text { research } \\ \text { Disputed authorship }\end{array} \\ \text { Authorship } & \text { Production or administrative error } \\ \text { Editor } & \end{array}$

Among the 9 reasons, we combined fraud, mistakes and inconsistent data since retracted articles led to the circulation of false information (labelled as "false information") and were compared to the 6 other reasons combined.

To assess the conformity of visibility of retraction to good practices, we decided to choose the COPE guidelines. Even if published in 2009, COPE guidelines were the formalization of common sense and informal practices of some journals. We therefore determined whether the retraction was mentioned on the pdf of the original article or not. Visibility of retractions was defined by three possibilities: 1) deletion of the article from the journal's website; 2) presence of the article with a mention of the retraction on the paper itself (either a comment at the beginning and/or at the end; or a clear indication for example printed diagonally across the paper) and/or mention on the journal's website; and 3) presence of the article with no mention.

Time to retractions and impact factors were compared using the Mann-Whitney or Kruskal-Wallis test. Visibility of retractions was compared using $\mathrm{Chi}^{2}$ test (or Fisher exact test where $\mathrm{Chi}^{2}$ test conditions were not fulfilled).

All analyses were performed using SAS v9.2 (Cary, North Carolina).

\section{Results}

Overall, 241 notices of retraction were retrieved. Concerning access, 209 were available by open access or accessible through our institution's subscription, 23 were found outside of our institution and 9 were impossible to locate.

These 241 notices of retraction represented 253 retractions (10 retracting 2 articles and 1 retracting 3 articles). After deleting 3 duplicate notices, 250 retractions remained available. Lastly, one "retracted retraction" and 5 partial 
retractions were discarded. Overall, 244 retractions were considered for analysis.

\section{Reason for retraction $(n=235)$}

As previously stated, formal retraction notices could not be retrieved for 9 of the retractions. Of the 235 retractions available, the reason was not given for 21 articles (9\%). For example, the only information given by some journals is that the article is being retracted. Sometimes, it is also specified "retracted by the authors" or "retracted to be consistent with the publisher policy on article withdrawal" or "retracted by the authors with the agreement of the journal editors and the publisher" without any other details.

The most cited reasons were mistakes $(n=65,28 \%)$, plagiarism $(\mathrm{n}=48,20 \%)$, fraud $(\mathrm{n}=34,14 \%)$ and overlap $(\mathrm{n}=25,11 \%)$ (Table 2).

The reasons are also presented according to countries in Table 2. In India and Japan, the most frequent reason was fraud, representing $43 \%$ for India (15/35) and $48 \%$ for Japan (12/25). In China, it was plagiarism with 34\% (10/29); whereas in the USA the main reason was mistakes at $60 \%(31 / 52)$ and plagiarism at $36 \%$ for United Kingdom (4/11).

Time to retraction and impact factors are compared between fraud, mistakes and plagiarism in Table 3.

\section{Mention of retraction on the original article $(n=233)$}

Of the 244 original articles, 11 could not be retrieved because they had to be paid for online or were printed articles or impossible to locate. We therefore found the original paper or its location for 233 retractions (95\%). Of these 233 retracted original articles, 139 (60\%) were available with a mention of the retraction either on the article or on the journal's website, $52(22 \%)$ were available with no mention and $42(18 \%)$ had been completely deleted (the publication concerned was no longer available on the journal's website) (Table 4). For articles with at least one mention, 101 (73\%) had a mention both on the article and the website, for $22(16 \%)$ the mention only featured on the website, $14(10 \%)$ only on the article and the 2 last cases (1\%) were 1) an empty pdf marked "retraction" with no mention on the website and 2 ) an article with a mention on the website for which the paper was no longer available in pdf format but which was available as html text. For the 115 papers which mentioned the retraction on the original article, $80(70 \%)$ had a clear indication and $35(30 \%)$ had notes at the beginning and/or at the end of the paper (Table 4).

Visibility of retraction on original articles was significantly higher for false information $(\mathrm{p}=0.003)$. Among the 106 articles with false information, 75 (71\%) had a mention compared to $64 / 127$ articles $(50 \%)$ retracted for other reasons; the rate of deleted articles was lower for false information compared to other reasons (11 (10\%) vs $31(24 \%))$; finally, the rate of articles available with no mention was similar (20 (19\%) vs $32(25 \%))$.

\section{Discussion}

The most frequent reasons for retraction in 2008 were mistakes (28\%), followed by plagiarism (20\%) and fraud (14\%), and journals insufficiently followed the retraction good practices formalized by the 2009 COPE guidelines.

All investigations into Medline retractions have highlighted the fact that it is difficult to find formal retraction notices containing the reason for retraction (studies found that formal explanation was unavailable for $5 \%$ [10], $11 \%$ [15], 12\% [16], 18\% [11]). Here, the content of the retraction was not explicit for 21 retractions (9\%). As recommended in previous studies, editors should always provide the precise reason for retraction. Sometimes obtaining the formal retraction notice is subject to a pay-per-view fee, and is therefore linked to the institution's membership. One study specified that the search was restricted to articles accessible within the institution [10], another specified that 46 notices (5.8\%) could not be retrieved [11], the other studies did not specify these cases were excluded or counted them as "reason

Table 2 Reasons for retraction ranked according to countries with at least 10 retractions in 2008

\begin{tabular}{|c|c|c|c|c|c|c|c|c|c|c|c|}
\hline & Total & Mistakes & Plagiarism & Fraud & Overlap & $\begin{array}{c}\text { Not } \\
\text { detailed }\end{array}$ & Authorship & Inconsistent data & $\begin{array}{l}\text { Property or legal } \\
\text { concerns }\end{array}$ & Editor & Ethics \\
\hline Total & 235 & 65 & 48 & 34 & 25 & 21 & 12 & 11 & 8 & 8 & 3 \\
\hline USA & 52 & $31(48)$ & $2(4)$ & $3(9)$ & $5(20)$ & $4(19)$ & $1(8)$ & $3(27)$ & $2(25)$ & $1(13)$ & \\
\hline India & 35 & $2(3)$ & $6(13)$ & $15(44)$ & $8(32)$ & $1(5)$ & $1(8)$ & $1(9)$ & & $1(13)$ & \\
\hline China & 29 & $7(11)$ & $10(21)$ & . & $2(8)$ & $3(14)$ & $3(25)$ & $1(9)$ & $2(25)$ & $1(13)$ & \\
\hline Japan & 25 & $3(5)$ & $2(4)$ & $12(35)$ & $2(8)$ & $2(10)$ & & $2(18)$ & . & & $2(67)$ \\
\hline United Kingdom & 11 & $3(5)$ & $4(8)$ & $1(3)$ & . & $2(10)$ & & $1(9)$ & . & . & 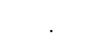 \\
\hline Korea & 11 & $5(8)$ & 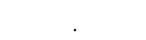 & $1(3)$ & . & $1(5)$ & . & & $2(25)$ & $2(25)$ & \\
\hline
\end{tabular}

Values are $\mathrm{n}$ (column percentage). Column percentage = number of given reason in a country/ total for this reason; allowing to see which countries contribute the most to each reason.

The column percentages do not add to $100 \%$ because some countries were not reported in the table. 
Table 3 Comparison of the 3 main reasons for retraction by impact factor, time to retraction and visibility of retractions

\begin{tabular}{|c|c|c|c|c|}
\hline & Fraud & Mistakes & Plagiarism & p-value \\
\hline \multirow{2}{*}{ Impact factor $(n=137)$} & 4.9 & 7.2 & 2.3 & \multirow{2}{*}{$<0.0001$} \\
\hline & $(3.2,2.9-14.6)$ & $(4.1,0.7-31.4)$ & $(1.9,0.3-9.8)$ & \\
\hline \multirow[t]{2}{*}{ Time to retraction $(n=244)$, years } & 2.2 & 2.5 & 3.2 & \multirow{2}{*}{0.722} \\
\hline & $(2,0-8)$ & $(2,0-10)$ & $(2,0-10)$ & \\
\hline Publication year of retraction $v$ s original article $(n=244), n(\%)$ & & & & 0.024 \\
\hline same year & $2(6)$ & $11(17)$ & $8(17)$ & \\
\hline 1 to 5 years & $31(91)$ & $47(72)$ & $29(60)$ & \\
\hline$>5$ years & $1(3)$ & $7(11)$ & $11(23)$ & \\
\hline Visibility $(n=233), n$ (\%) & & & & 0.057 \\
\hline mention & $28(82)$ & $38(62)$ & $22(51)$ & \\
\hline no mention & $5(15)$ & $15(25)$ & $12(28)$ & \\
\hline deletion & $1(3)$ & $8(13)$ & $9(21)$ & \\
\hline
\end{tabular}

Values are mean (median, min-max) unless otherwise specified.

unclear". Overall, in our study, 9 retractions were not available even with payment. The fact that retraction notices are not freely available and when available, are not explicit, contravenes the COPE guidelines [14] and should be a priority for journals as they are essential for the reader's understanding of whether the results still hold.

However, editors are not always willing to retract articles [19]. It is therefore necessary that all journals implement a retraction policy, indeed in a 2004 review it was

Table 4 Mention of retraction on the original article

\begin{tabular}{|c|c|}
\hline & n (\%) \\
\hline \multicolumn{2}{|l|}{ Original article $(n=233)$ : } \\
\hline Deletion & $42(18)$ \\
\hline No Mention & $52(22)$ \\
\hline Mention & $139(60)$ \\
\hline both website and article & $101(43)$ \\
\hline article & $14(6)$ \\
\hline website & $22(10)$ \\
\hline other & $2(1)$ \\
\hline \multicolumn{2}{|c|}{ If mention available on article $(n=115)$, details: } \\
\hline At least a clear indication $\dagger$ & $80(70)$ \\
\hline present without notes & $72(63)$ \\
\hline present with notes at the end & $5(4)$ \\
\hline present with notes at the beginning & $3(3)$ \\
\hline Notes only & $35(30)$ \\
\hline at the end & 9 (8) \\
\hline at the beginning & $19(16)$ \\
\hline both at the beginning and the end & $7(6)$ \\
\hline
\end{tabular}

shown that only $18 \%$ had a dedicated policy [20]. The way to handle mistakes is sometimes controversial: some recommend to publish corrections [7], whereas others state that they should be full retractions [14]. Practices are not homogeneous [21], and retractions for mistakes are regularly published.

It has already been demonstrated that the retracted literature continues to be cited $[18,22]$. One of the explanations might be that retractions are not correctly reported on original article. We found that the mention of the retraction was incorrect for half of the retractions: the article was either completely deleted, or was still available with no mention. This is similar to the $45 \%$ found by Steen [11]. The retraction good practices formalized by the COPE guidelines [14] are probably not well known or respected. Clear rules should be applied to ensure that this literature is identified as retracted. To be consistent with full transparency of publication, it is inappropriate to completely remove a retracted article from the website of a journal. As long as a clear mention of the retraction is available on both the journal website and the article, scientists must still have access. Some publishers are probably afraid of the circulation of false information, particularly of fraudulent data, and retracted articles continue to be removed from printed or online versions of some journals.

We also decided for the purposes of this study to combine fraud, inconsistent data and mistakes to estimate what proportion of retracted articles might have damaged the body of knowledge. Other reasons include, of course, misconduct however the information in these papers remains true. Steen has also shown that many patients are put at risk since approximately 2472.6 subjects per retracted paper were enrolled in subsequent studies using this retracted research [23]. Recently, the 
CrossMark system has been developed following the collaboration between several publishers to standardize the way of providing readers how to locate the current version of an article [24]. If one journal applied the CrossMark icon on every pdf, it is to try to maintain the content of published articles and, by clicking on it, to warn readers if changes have occurred. In the future, this system may reduce citations to retracted articles.

We cross-tabulated reasons for retraction with countries. However, retraction rates by country should be interpreted relative to publication rate: the USA represents $22 \%$ of retractions but also represents the highest number of publication. The aim of this study was to provide a global description of retraction, and due to the low numbers in each category we did not provide any statistical comparison of countries. Good practices should be better disseminated to authors and editors in order to educate them and raise their awareness to better prevent misconduct; however fraud will not be deterred by this dissemination. We found similar rates as Wager [10]: 28\% for mistakes vs. $28 \%, 20 \%$ for plagiarism vs. $16 \%$ and $14 \%$ for fraud vs. $11 \%$.

We noticed an association between impact factor and reasons for retraction with mistakes being published in higher impact factor journals. This could be explained by the fact that some authors might hurry to publish in a prestigious journal without taking enough time to check their data. When a paper deals with a hot topic, journals tend to publish special issues very rapidly. Moreover, mistakes are also very frequent in the USA where researchers can be subject to greater pressure and are more inclined to submit to prestigious international journals. The publications by Steen and Fang also found that higher impact factor journals were more prone to retraction $[12,25]$.

\section{Conclusion}

It would be useful to use a standard retraction form with for example a check list of major reason, which would then leave the editor free to provide the reader with any further information. Original articles should remain available with a clear mention of the retraction, and not only a mention on the journal website or in notes at the beginning or end of the article. This is probably on the COPE agenda, and our work can contribute to proposing definitions.

\section{Competing interest}

The authors declare that they have no competing interests.

\section{Authors' contributions}

ED declares that she designed the study, assessed the retractions, analysed the data, interpreted the data and wrote the manuscript. LH declares that she designed the study, assessed the retractions, interpreted the data, participated in drafting the manuscript and that she has read and approved the final version. GS declares that she retrieved the retraction notices, assessed the retractions, participated in drafting the manuscript and that she has read and approved the final version. HM declares that he participated in analysis planning, interpreted the data, participated in drafting the manuscript and that he has read and approved the final version. All authors read and approved the final manuscript.

\section{Authors' information}

$\mathrm{ED}$ is a senior researcher (PhD), LH is a senior researcher (PharmD, PhD), GS is a junior researcher (PharmD), HM is a senior researcher (MD).

\section{Acknowledgements}

We would like to thank Florence Bouriot from the documentation center of Hospices Civils de Lyon for retrieving articles and notices of retraction, Joan Marsh (Wiley, London, UK), Paola De Castro (Istituto Superiore di Sanità, Roma, Italy), Barbara Gastel (Texas A\&M Health Science Center, USA), Shouchu Qian (Chinese Medical Association, China) who helped us to retrieve articles; and Kim Barrett for proofreading.

\section{Author details}

${ }^{1}$ Hospices Civils de Lyon, Pôle Information Médicale Evaluation Recherche, Unité de Recherche Clinique, Lyon F-69003, France. ${ }^{2}$ RECIF, EAM Santé Individu Société 4128, Université de Lyon, Lyon F-69003, France. ${ }^{3}$ Université Lyon 1, Lyon F-69003, France.

Received: 6 November 2012 Accepted: 11 June 2013

Published: 19 June 2013

\section{References}

1. Uniform Requirements for Manuscripts Submitted to Biomedical Journals. [www.icmje.org].

2. Drazen JM, Van Der Weyden MB, Sahni P, Rosenberg J, Marusic A, Laine C, Kotzin S, Horton R, Hebert PC, Haug C, et al: Uniform format for disclosure of competing interests in ICMJE journals. Lancet 2009, 374:1395-1396.

3. Can peer review police fraud? Nat Neurosci 2006, 9:149.

4. Martinson BC, Anderson MS, De Vries R: Scientists behaving badly. Nature 2005, 435:737-738.

5. Steen RG: Misinformation in the medical literature: What role do error and fraud play? J Med Ethics 2011, 37:498-503.

6. Sox HC, Rennie D: Research misconduct, retraction, and cleansing the medical literature: lessons from the Poehlman case. Ann Intern Med 2006, 144:609-613.

7. Smith R: When to retract? BMJ 2003, 327:883-884.

8. Marcus A: Retractions Come in Boldt Case, Likely Most for Single Author. Probe finds 88 papers lacked ethics approval. Anesthesiology News 2011, 37.

9. Rittner HL, Kranke P, Schafer M, Roewer N, Brack A: [What can we learn from the Scott Reuben case? Scientific misconduct in anaesthesiology]. Anaesthesist 2009, 58:1199-1209.

10. Wager $E$, Williams $P$ : Why and how do journals retract articles? An analysis of Medline retractions 1988-2008. J Med Ethics 2011, 37:567-570.

11. Steen RG: Retractions in the scientific literature: is the incidence of research fraud increasing? J Med Ethics 2011, 37:249-253.

12. Steen RG: Retractions in the scientific literature: do authors deliberately commit research fraud? J Med Ethics 2011, 37:113-117.

13. Corbyn Z: Retractions up tenfold. Higher Education: Times; 2009.

14. COPE: Retraction guidelines; 2009 [http://www.publicationethics.org/files/ retraction\%20guidelines.pdf].

15. Nath SB, Marcus SC, Druss BG: Retractions in the research literature: misconduct or mistakes? Med J Aust 2006, 185:152-154.

16. Redman BK, Yarandi HN, Merz JF: Empirical developments in retraction. J Med Ethics 2008, 34:807-809.

17. Budd JM, Sievert M, Schultz TR: Phenomena of retraction: reasons for retraction and citations to the publications. JAMA 1998, 280:296-297.

18. Budd JM, Sievert M, Schultz TR, Scoville C: Effects of article retraction on citation and practice in medicine. Bull Med Libr Assoc 1999, 87:437-443.

19. Newman M: The rules of retraction. BMJ, 341:c6985.

20. Atlas MC: Retraction policies of high-impact biomedical journals. J Med Libr Assoc 2004, 92:242-250.

21. Williams $P$, Wager E: Exploring why and how journal editors retract articles: findings from a qualitative study. Sci Eng Ethics 2013, 19:1-11. 
22. Pfeifer MP, Snodgrass GL: The continued use of retracted, invalid scientific literature. JAMA 1990, 263:1420-1423.

23. Steen RG: Retractions in the medical literature: how many patients are put at risk by flawed research? J Med Ethics 2011, 37:688-692.

24. CrossMark Support Site. [http://crossmarksupport.crossref.org/].

25. Fang FC, Casadevall A: Retracted Science and the Retraction Index. Infect Immun 2011, 79:3855-3859.

doi:10.1186/1756-0500-6-238

Cite this article as: Decullier et al.: Visibility of retractions: a cross-

sectional one-year study. BMC Research Notes 2013 6:238.

\section{Submit your next manuscript to BioMed Central and take full advantage of:}

- Convenient online submission

- Thorough peer review

- No space constraints or color figure charges

- Immediate publication on acceptance

- Inclusion in PubMed, CAS, Scopus and Google Scholar

- Research which is freely available for redistribution 